\title{
Construction of a low budget ozone generator prototype
}

\author{
Laércio Ferro Camboim ${ }^{1}$, Janine Aline De Souza Silva ${ }^{2}$, \\ Fernando Carlos Ferreira De Oliveira ${ }^{3}$, Adriana Maria Cunha Da Silva ${ }^{4}$, \\ Fabiano Almeida Nascimento ${ }^{5}$, Luiz Antônio Pimentel Cavalcanti ${ }^{6}$ \\ ${ }^{1}$ (Electrical Engineering Department, Federal Institute of Bahia, Brazil) \\ ${ }^{2}$ (Fisheries Engineering Department, University of Bahia State, Brazil) \\ ${ }^{3}$ (Fisheries Engineering Department, University of Bahia State, Brazil) \\ ${ }^{4}$ (Academic Department, University of Bahia State, Brazil) \\ ${ }^{5}$ (Electrical Engineering Department, Federal Institute of Bahia, Brazil) \\ ${ }^{6}$ (Academic Department, Federal Institute of Bahia, Brazil)
}

\begin{abstract}
Industries advance causes serious damages to environment, these impacts are mainly visibly due to pollution emitted as gases and effluents. However, most companies are looking for alternatives that are both fast and efficient in reducing environmental degradation. Regarding effluents emission, there are recent researches that seek methods to treat wastewater effectively in industrial processes and, among these methods, ozone use stands out. This paper presents the development of a low cost sustainable ozone generator prototype with the purpose of producing gas by using corona effect, formed by high voltage generators using photovoltaic panels as power supply. In its construction recycled materials were used. The project aimed to use electronic concepts as a way to increase the apparatus efficiency, looking forwards to improve the gas application in liquid effluents treatment. After the prototype construction, ozone production was certificated by bubbling out the reactor directly into a solution of soluble iodine / potassium iodide. Ozone presence was observed by the solution coloration changing from colorless to intense dark blue. At the end of the work, experiments were carried out at the treatment of water from fish farms, in which the gas performance in the regulation of quality indicators, such as salinity, $\mathrm{pH}$, dissolved oxygen and Electrical conductivity.
\end{abstract}

Keywords: Corona Effect, Effluent Treatment, Ozone Generator, Photovoltaic Energy

\section{Introduction}

One of the most common phenomena found in electrical engineering is the corona effect, which is an electrostatic discharge mechanism due to ionization of an insulating material, generally seen in gases subjected to an electric field with sufficient intensity to break its dielectric strength [1]. In electric power transmission lines corona effect causes some disturbances, since it is energy loss for energy sellers, what represents hundreds of kilowatts per kilometer of transmission lines with extra high voltage [2]. However, the effect also known as corona discharge is not only disadvantageous; it has some industrial applications, such as the undesirable electrical loads removal on aircraft surfaces, and especially in ozone production [3].

One of ozone applications is the effluents treatment, which has proved to be quite efficient and adequate at the elimination of substances resistant to degradation in conventional treatment systems, standing out when compared to chlorine and hydrogen peroxide. This technique has been strongly suggested because it can minimize water turbidity and chemical oxygen demand [4]. Recent advances in this way of treatment have resulted in a considerable reduction of costs involved in its application, making it increasingly attractive [5].

Among the producing gas methods, some can be highlighted: the electrolysis obtained, characterized by the difficulty of handling the ozone; The ultraviolet radiation, which does not meet the needs of the industry due to its high cost and low yield and finally the production by corona discharge, which produces significant amounts, being the most used method to obtain ozone [6]. Due to high molecule instability, the gas storage becomes impracticable, implying in the necessity of an in situ production. Ozonation is a chemical reaction of gas absorption process where the limiting step of the process is the mass transfer due to the low solubility of ozone in the water [7]. Corona effect generates ozone through a high voltage process that produces a strong enough electric field to break the dielectric strength of the air between the electrodes, where the free electrons reach high speeds, breaking the oxygen molecules and forming ozone when regrouping, a high oxidizing power compound [1]. The electric discharge process, which consists in the application of an electrical potential difference at the reactor electrodes, can be obtained from the use of a flyback converter, excited by a high frequency oscillator acting as a high voltage transformer. Among the existing circuits, the Hartley oscillator stands out because it meets the demand for high frequency and its use makes possible the utilization of higher current values than other oscillators types, which implies in a higher power at the transformers output [1]. 
Solar energy has a great utility as a renewable and sustainable power supply, even though there are challenges that still have to be overcome, such as the cost of photovoltaic modules and the reliability of the associated electronic equipment. The use of photovoltaic panels in buildings and industry has shown to be an economically and environmentally viable alternative with potential on reducing costs while decreasing the impacts caused by consumer's high demand for electricity [8]. This work aimed to evaluate the efficiency of a low cost ozone generator prototype from the reuse of scrap materials from computers and solid waste such as PET bottles, metal pipes and leftover electrical installations. Its operating principle was based on the production of ozone by corona effect, having photovoltaic panels as power supply, applying electronic concepts for the construction of a stable and sustainable system. This system intends to make the ozonation process feasible in laboratory scale for its use in studies and effluents treatment.

\section{Theoretical Framework}

Corona effect occurs when an intense electric field accelerates the existing electrons around a conductor, causing them to acquire enough energy to collide with other atoms and thus to release more electrons. When the collision happens with sufficient force, the hit atom reaches a higher energy state, where to get back to its initial state, it is necessary to release that energy, which is released in form of light, heat, acoustic energy and / or electromagnetic radiation [9]. A striking feature is that this phenomenon becomes more present at the ends of the conductors, since the electric charges tend to accumulate in more pointed places, making the electric field more intense in these points due to the great density of loads, this fact is known as Tips theory. A cylindrical conductor with a very short cross section can have the same effect, since the loads accumulate only on its surface, which in turn has a small area, causing a great electric charges density [10]. Choosing a suitable geometry for a device capable of aiding in corona studies and having significant ozone production is a fundamental point of the process, since certain configurations produce arcs more easily than others. The arrangement in coaxial cylinders is often used, since from a good dimensioning as to its radial dimensions, it is possible to obtain a greater electric field without a total dielectric rigidity rupture of the air [11]

Fig. 1 shows a device with coaxial cylinders configuration. As can be observed, the electric field lines for this configuration are radial, with their modulus being in function of the distance $\mathrm{x}$ from the cylinder center.

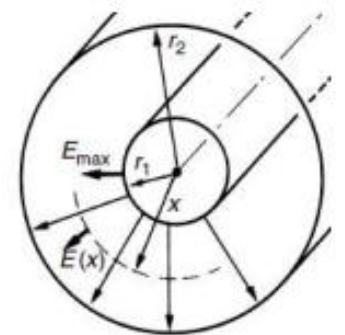

Figure 1 - Electrical field in coaxial cylinders [11]

When an electrical potential difference is applied between the two cylinders, their surfaces will be uniformly loaded with a certain amount of charges per area unit. It is possible to determine the value of the electric field in the space between the two cylinders through Gauss's law, as can be seen in (1):

$$
E(x)=\frac{\rho}{2 \pi \varepsilon} \cdot \frac{1}{x}
$$

Where, $\rho$ is charge density, $\epsilon$ is permittivity constant and $\mathrm{x}$ is the distance between the cylinders;

Electric field strength can also be obtained from the negative gradient of the potential difference as shown (2) and (3):

$$
E=-\nabla V
$$

Than,

$$
E(x)=\frac{V}{\ln \left(r_{2} / r_{1}\right)} \cdot \frac{1}{x}
$$


Where, $\mathrm{R}_{1}$ is the radius of the outer cylinder, $\mathrm{R}_{2}$ is the radius of the inner cylinder, $\mathrm{V}$ the electrical difference of potential and $\mathrm{x}$ the distance between the cylinder's center. When the voltage level at the smaller cylinder reaches rupture level, a stabilized corona discharge or a complete rupture will occur. It is then possible to determine with (3) the parameters for maximum stabilized corona effect, without breaking the dielectric rigidity of the air completely, which is the optimal point ozone production [11].

\section{Materials And Methods}

The methodology for system development was constructed, beginning with the photovoltaic module and finishing with the ozone reactor. Fig. 2 shows in block diagram the prototype operation.

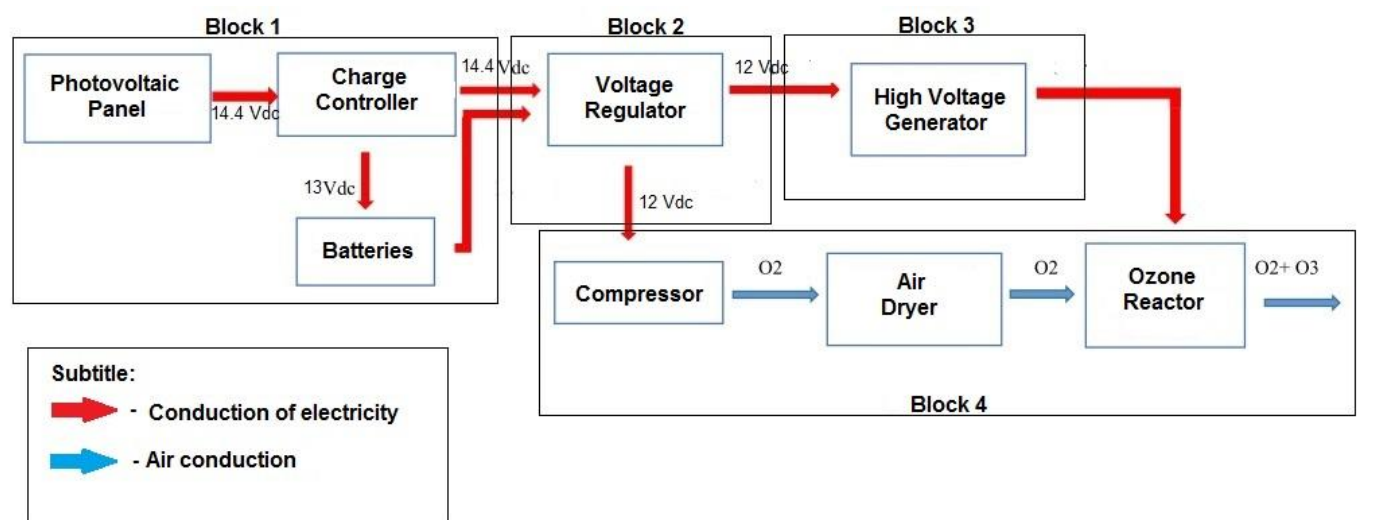

Figure 2 - Block diagram of prototype operation

\subsection{POWER SuPPLY}

Circuit power supply comes from a reused photovoltaic plate of leftovers from an electrical installation at Federal Institute of Bahia Paulo Afonso campus, having an output voltage of $14.4 \mathrm{Vdc}$ with $100 \mathrm{Wp}$ nominal power. Therefore, in aiming to make the prototype operation independent of directly solar incidence, a set of batteries recovered from notebooks scraps was introduced. Since it is an isolated photovoltaic system, a load controller was necessary to recharge the battery when needed and to stop the power supply when it is fully charged, as shown in Fig. 3.

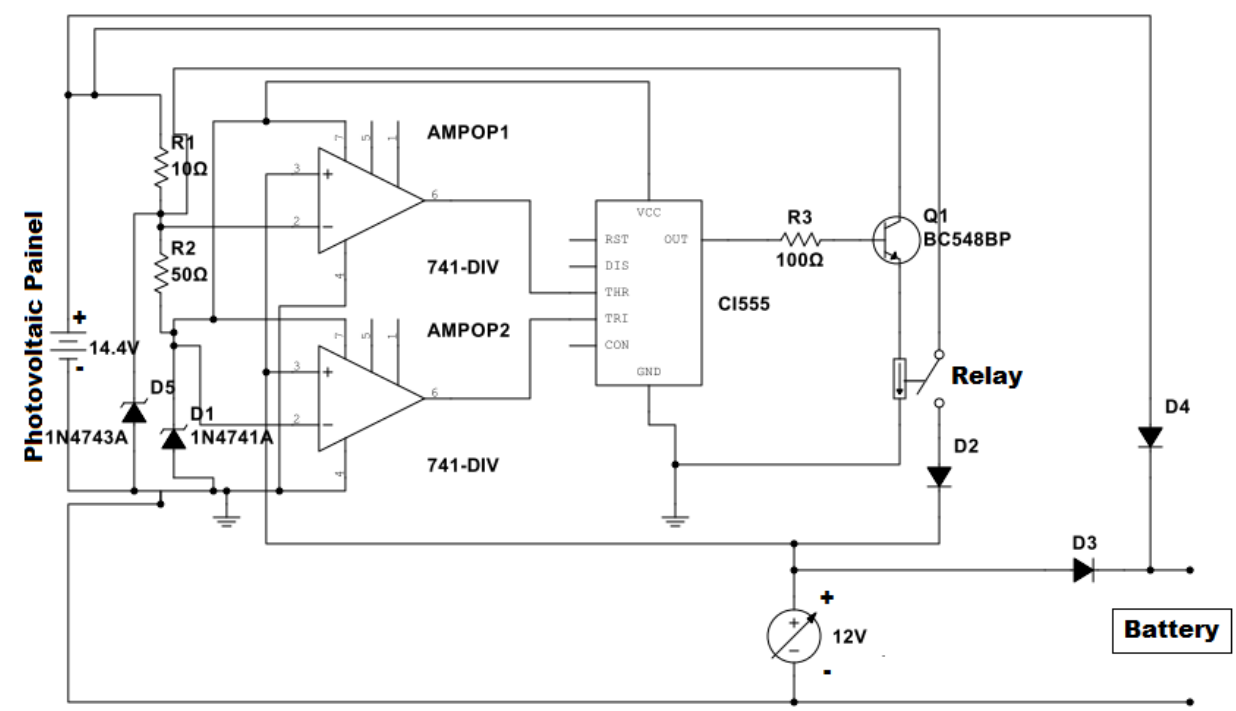

Figure 3 - Charge controller circuit

\subsection{VOLTAGE REgULATION}

For the correct circuit operation, as well as its protection against overloads and peak currents, voltage regulators were implemented, as indicated by block 2 of Fig. 2, using 2N3055 transistors, as shown in Fig. 4. 


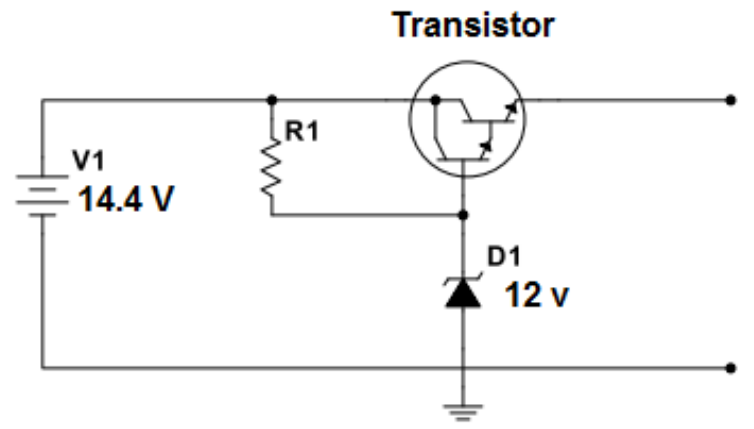

Figure 4 - Voltage regulation

\subsection{High Voltage}

In order to have ozone production by corona effect, a flyback converter excited by a Hartley oscillator was used. This system functions as a transformer, raising the input voltage to a level that is capable of breaking the air dielectric strength. The circuit that makes up the high voltage generator formed by Hartley and flyback oscillator cell is shown in Fig. 5.

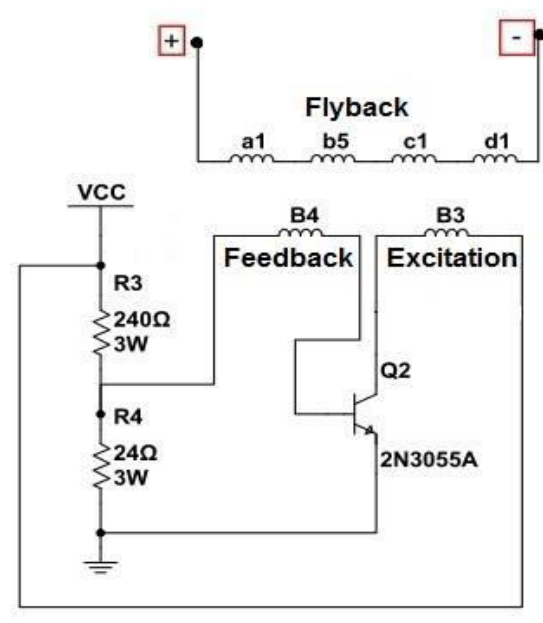

Figure 5 - High voltage generator

\subsection{AIR PUMPING}

Aiming to blow air inside the ozone reactor, it was built-in the generator a mini compressor, consisting of a $12 \mathrm{Vdc}$ motor coupled to a diaphragm recovered from a nebulizer scrap, which is connected to a chamber with silica to reduce air humidity, making it suitable to enter the ozone reactor.

\subsection{AIR IONIZATION}

Looking forward to properly built the ozone reactor, it was necessary an evaluation of the proper geometry to promote a greater contact surface between the part where occurs corona effect and the air. For this, two geometries was analyzed, the arrangement in parallel plates and the arrangement by coaxial cylinders.

PET bottle caps were used to serve as covers in the reactor, since the copper tube has the outside diameter that fits neatly into a PET bottle cap. On this way, a cover has been placed on each side of the metal tube, where there were only two holes in each side, one to support the inner wire and the other to air inlet and outlet.

\subsection{Final MODEL} shown in Fig. 6.

Prototype was constructed as detailed in the previous sections and presented final configuration as 


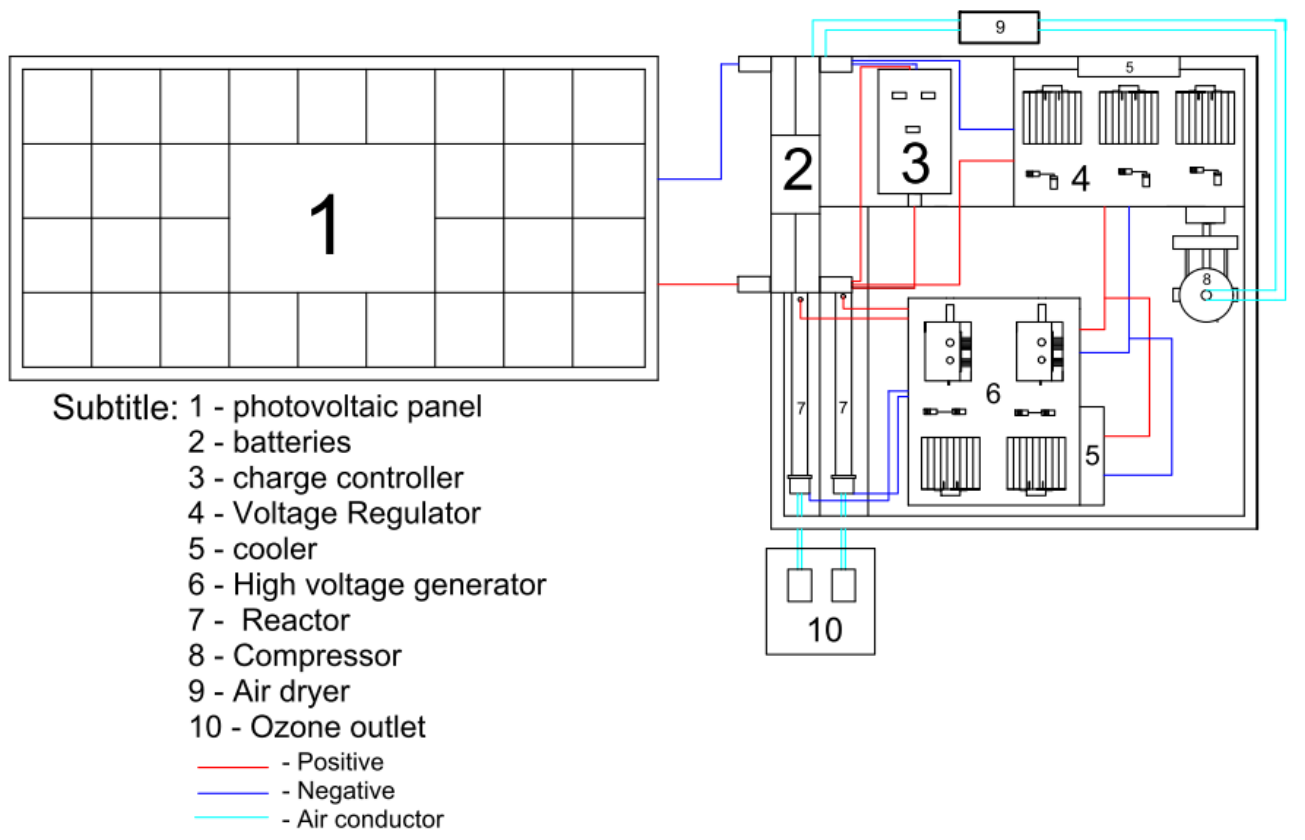

Figure 6 - Block diagram of final prototype assembly

\subsection{Prototype Evaluation}

Prototype evaluation process consisted of two tests: the first to certify that there was ozone production and the second to observe the oxidizing gas effect in fish farming water treatment. In order to perform the first experiment, prototype output gas was pumped into a solution containing soluble starch and potassium iodide, solution with no coloration, however in the presence of ozone the iodide is oxidized into iodine, which reacts with starch, changing the solution color into dark blue.

Finally, to determine the device efficiency in effluents treatment, a sample of water contained in a tank of tilapia farming was obtained at the Department of Fisheries Engineering from the State University of Bahia (UNEB), in which averaged 65 fishes per cubic meter. Physical-chemical parameters of the obtained water from tilapia farming were carried out before and after treatment with ozone-generating prototype. The treatment using ozone generator was by direct bubbling of the gas inside the raw water with exposure time of $20 \mathrm{~min}$. Parameters such as $\mathrm{pH}$, salinity, conductivity and dissolved oxygen were measured by the multiparameter device YSI Professional Plus model.

\section{Results And Discussion}

The prototype was designed and the main tests was done and analyzed, the following results were obtained and are present separately.

\subsection{PoWer Supply}

The correct prototype functioning was observed when it was fed with a $14.4 \mathrm{~V}$ supply in parallel with the battery bank and the load controller. The developed load controller also presented satisfactory results, when connecting to batteries bank in which it had a voltage of $11.4 \mathrm{Vdc}$, then the device was triggered and remained in the same state until the batteries reached the voltage of $13,3 \mathrm{Vdc}$.

\subsection{Voltage Regulation}

The voltage regulation as well as the current control worked successfully. It was verified a better performance when the power factor of one of the flybacks is corrected with a capacitor of $20 \mathrm{nF}$ and fed with a 9 Vdc supply. The second flyback did not show the same result, but it was powered with a $12 \mathrm{Vdc}$ supply, however it was necessary to make its voltage regulator cell more robust by adding another $2 \mathrm{~N} 3055$ transistor in parallel with the existing one. Since the current demanded by the compressor is $2 \mathrm{~A}$ its voltage regulator was built with a TIP122 transistor.

\subsection{High Voltage}

In order to increase corona effect intensity, one of the flybacks power factor was corrected, as well as its power voltage, as mentioned in the previous session. 


\subsection{Air Pumping ANd Ionization}

Developed compressor presented correct functioning, being able to pump the air through the reactor, without heating or failure. It was observed that the reactor produced a corona effect along its length, without the presence of electric arcs, which according to [11] is the optimal point for ozone production.

For parallel plates arrangement, depending on the distance between the plates and the power supplied by the flyback, several arcs arose, where in an attempt to control them, it was observed that the incidence of corona occurred only at the plate borders, showing an unstable and inefficient system.

Then, the arrangement was evaluated by coaxial cylinders, where the outer cylinder was obtained from copper tubes rescued from broken bunkers found in the Federal Institute of Bahia deposit and for the inner section one of the eight twisted wires of a UTP cable was used. It was observed that at tubes edges, arcs appeared, disrupting the formation of ozone, so a plastic tube made by pen caps was wrapped in the inside of each cap, wrapping the wire without touching it, in order to increase the electrical permissiveness and avoid the arcs formation. This was the configuration where the greatest corona effect was obtained, without arcing appearance.

\subsection{Final Prototype Assembly}

After the necessary tests and corrections, the final prototype was ready for the tests as shown in Fig. 7.

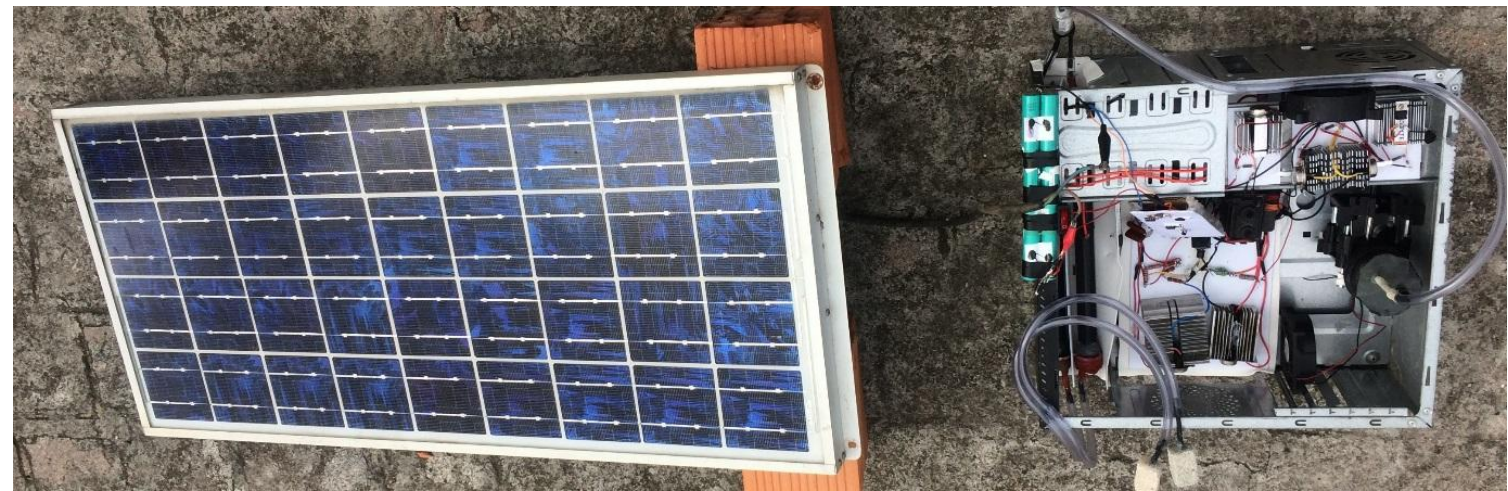

Figure 7 - Prototype assembled and ready for tests.

\subsection{Prototype Evaluation}

At the initial test stage we needed to prove that the reactor actually produced ozone satisfactorily and it could be proven in a simple and practical way. A solution with soluble starch and potassium iodide was prepared. In the presence of the ozone the iodide was oxidized to iodine, and the iodine formation was detected, as it reacts with the starch, modifying the solution color from colorless to dark blue or purple. Fig. 8a shows the solution of soluble starch and potassium iodide (colorless solution). Fig. 8b shows the dark blue solution due to iodide oxidation, proving ozone formation by the reactor.
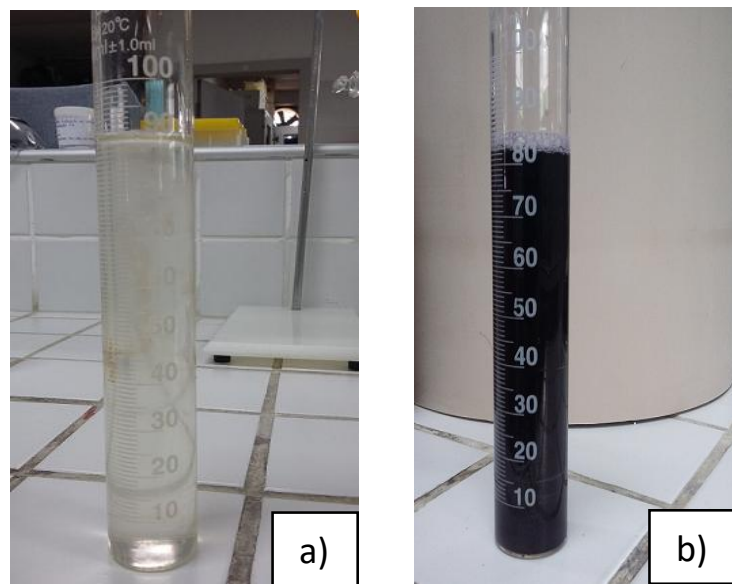

Figure 8 - Starch/iodine solution: a) Not oxidized solution; b) Oxidized solution

Starch is a polysaccharide that can be divided into two structures, amylose and amylopectin. The first is the linear part of the polymer chain and has helical conformation. We can better understand the dynamics of iodide oxidation when analyzed (4) and (6) 


$$
\begin{gathered}
\text { Starch }(a q)+I^{-}(a q) \rightarrow \text { Do not react } \\
I^{-}+I^{-} \rightarrow I_{2}+2 e^{-} \\
I^{-}+I_{2} \rightarrow I^{3-}
\end{gathered}
$$

Initially the starch does not react with iodide ion (4) and the solution remains colorless. When we convert the iodide ion to iodine, it reacts with another iodide ion, forming the molecule $\mathrm{I}^{3-}$, which forms a complex with starch whose structure is helical (tubular). The iodine binds within this structure forming a complex of dark blue coloration. The physical and chemical variables from raw water were evaluated as described in the methodology and are presented in Table 1. According to [12] pH values between 7 and 8.3 are considered optimal for psychology. The values obtained for the raw water of the tanks were 4.67 outside the range considered as ideal. After 20 min of treatment with ozonation prototype $\mathrm{pH}$ value increased to 7.21 within the limits considered ideal by the specialized literature.

Table 1- Physical and chemical parameters of raw and ozone treated water

\begin{tabular}{|c|c|c|}
\hline Parameter & Raw Water & Ozone Treated Water \\
\hline Temperature $\left({ }^{\circ} \mathrm{C}\right)$ & 26,6 & 26,7 \\
\hline $\mathrm{pH}$ & 4,67 & 7,21 \\
\hline Conductivity $(\mu \mathrm{s} / \mathrm{cm})$ & 1503 & 763 \\
\hline Dissolved Oxygen $(\mathrm{mg} / \mathrm{L})$ & 7,62 & 0,69 \\
\hline Salinity $(\mathrm{ppt})$ & 0,70 & 0,36 \\
\hline
\end{tabular}

According to authors, electrical conductivity indicates the capacity of water to conduct electric current, this variable provides important information about the tank metabolism, helping to detect sources of pollution in the system, and to assess the availability of nutrients in aquatic ecosystems. High values of electrical conductivity indicate a high degree of organic decomposition and, as shown in Table 1, the value obtained for raw water after treatment was reduced to $763 \mu \mathrm{s} / \mathrm{cm}$. According to [12] oxygen solubility in water depends on atmospheric pressure and water salinity. This variable is directly related to atmospheric pressure and inverse related with salinity. So the salinity reduction by almost $50 \%$ in this study case increases the availability of dissolved oxygen. In general, results obtained for the treatment of water from tilapia farming with the ozone generator prototype were satisfactory and its application in the treatment of such effluents configures only one of the several applications where the ozone generator can be used.

\section{Conclusion}

From the tests done with the prototype, ozone production obtained from corona effect was proven, being this gas used in water treatment, demonstrating the technical feasibility regard to construction of a sustainable ozone reactor using recycled and reused materials, as well as the possibility of effluents treatment by using this prototype. The recycled materials had a satisfactory behavior during the tests and the photovoltaic power system supplied the electric demand necessary for the device operation. Ozone production by the prototype was evaluated through the use of the produced gas in a reaction with potassium iodide, proving the existence of the gas that, acting as oxidant of the iodide, caused the colorless solution to turn into dark blue due to oxidation reaction of the iodide. It is also possible to affirm that is feasible to use the reactor on a larger scale, serving as an alternative effluents treatment in several applications. Corona effect, responsible for obtaining ozone, was controlled and constant respecting the electrical parameters observed in the electronic construction of flybacks. System stability indicated the necessary reliability for the treatment to take place during the required time to stabilize the effluent in order to obtain the desired chemical and physical quality parameters.

The ozone obtained from the built prototype was used to treat the effluent from fish farming, with a changing of $\mathrm{pH}$ index from 4.67 to 7.21 during a continuous treatment of 20 minutes. Satisfactory results during this treatment were also observed in the reducing of effluent salinity from $0.70 \mathrm{ppt}$ to $0.36 \mathrm{ppt}$ and in the water electrical conductivity that was reduced from $1503 \mu \mathrm{s} / \mathrm{cm}$ to $763 \mu \mathrm{s} / \mathrm{cm}$. Thus, the feasibility of prototype use for ozonation in laboratory scale is confirmed, in order to use the gas obtained in studies and treatment of effluents.

\section{Acknowledgements}

This research was supported by Federal Institute of Bahia (IFBA), we thank the Institute by providing equipment and working space for this project. 


\section{References}

[1] M. S. Lopes, Remoção do Fármaco Ácido Mefenâmico em Água Via Oxidação por Cloro e por Ozônio, Bachelor diss. Universidade Estadual Paulista, Rio Claro, SP, 2016.

[2] G. F. Wedy, Inclusão do efeito corona em modelos de linhas de transmissão bifásica utilizando a técnica de variáveis de estado, Master diss., Universidade do Estado de São Paulo, São Paulo, SP, 2009.

[3] G. Schiavon, et al, Projeto e Análise de um sistema gerador de ozônio para remoção de cor de efluente têxtil, Revista Unisal, v. 16, number 18, 2013.

[4] A. K. S. Fernandes, Reuso de água no processamento de jeans na indústria têxtil, Master diss., Universidade Federal do Rio Grande do Norte, Natal, RN, 2010.

[5] S. Castilhos. Emprego de ozonização para o tratamento de efluente têxtil. Bachelor diss. Universidade Tecnológica Federal do Paraná, Curitiba, PR, 2015.

[6] W. Maidana, C. Kreutz, R. Bernardi, Análise de clarificação de efluentes industriais utilizando gerador eletrônico de ozônio. XX Brazilian Congress of Chemical Engineering - COBEQ, São Paulo - SP, 2014.

[7] A. M. D. Fornari, Geração de microbolhas de ozônio através de materiais porosos para aplicação em tratamento de efluentes. Bachelor diss. Universidade Federal do Rio Grande do Sul, Porto Alegre, RS, 2011.

[8] S. P. Ísis, Integração de painéis solares fotovoltaicos em edificações residenciais e sua contribuição em um alimentador de energia de zona urbana mista. Master diss. Universidade Federal de Santa Catarina, Florianópolis, SC, 2009.

[9] A. S. S. Alessandro, Metodologia de cálculo da tensão crítica de isolamento de linhas de transmissão de energia elétrica usando o método dos elementos finitos. Master diss. Universidade Federal de Juiz de Fora, Juiz de Fora, MG, 2010.

[10] E. B. Giudice et al, Desenvolvimento de Condutores Compactos Aplicados a Projetos de Linhas Aéreas de Transmissão. II Congresso de Inovação Tecnológica em Energia Elétrica, São Paulo - SP, 2003.

[11] E. Kuffel, W. S. Zaengl, J. Kuffel, Princípio das Operações Unitárias, BOSTON: Butterworth-Heinemann, 2000.

[12] L. K. S. Gomes et al, Análise de alguns parâmetros físico-químicos da água em tanques para cultivo de tilápias e tambaquis. XIII Jornada de Ensino, Pesquisa e Extensão - JEPEX, Recife - PE, 2013. 